\title{
The Downsian model of electoral participation: Formal theory and empirical analysis of the constituency size effect*
}

\author{
STEPHEN HANSEN \\ THOMAS R. PALFREY \\ HOWARD ROSENTHAL \\ Carnegie-Mellon University, Schenley Park, Pittsburgh, PA 15213
}

\begin{abstract}
This paper applies a game-theoretic model of participation under uncertainty to investigate the negative relationship between constituency size and voter turnout rates: the constituency size effect. We find that this theoretical model accounts for almost all of the variation in turnout due to size in cross sectional data from school budget referenda.
\end{abstract}

\section{Introduction}

We seek to bring together theoretical and empirical analysis of electoral participation in a rigorous fashion. The modern, positive theory of participation was initiated by Downs (1957) and is represented by the well-known equation:

$$
\mathbf{R}=\mathrm{pB}-\mathrm{c}+\mathrm{d}
$$

where $\mathbf{R}=$ the net return from voting

$\mathrm{p}=$ the probability the voter will be decisive

$B=$ the utility differential that results when the act of voting is decisive

$c=$ positive costs of voting not associated with the outcome

$\mathrm{d}=$ positive benefits of voting not associated with the outcome.

For many years, the theory remained primitive because the probability $p$ was given exogenously (e.g. Riker and Ordeshook, 1968) rather than arising

* This work has benefitted from comments made at presentations at the political economy seminars at Carnegie-Mellon, Pennsylvania, and Stanford and at the Weingart Conference on Formal Models of Voting at Caltech. In particular, we thank Robert Inman and Douglas Rivers for independently pointing out that multiple equilibria posed a problem for maximum likelihood estimation and Rivers for simplifying the derivation of the likelihood function. We also thank the referee for useful comments. 
directly as a consequence of self-interested behavior by voters. If many people voted, it could be readily argued that $p$ had to be so infinitesimal that only individuals with negative net costs of voting $(c-d)$ would vote. But if, as some believed (e.g. Ledyard, 1984), the net costs of voting were positive, then infinitesimal $p$ implied that no one would vote. Hence, everyone would be decisive and $\mathrm{p}$ would equal one.

This 'paradox of not voting' led to Ledyard's (1984) elaboration of the Downsian model, bringing a game-theoretic rather than decision-theoretic focus to the problem by deriving $p$ endogenously as the result of each voter's acting in consequence of his or her anticipations of the actions of other voters. Just as important, Ledyard introduced incomplete information to reflect the fact that voters are uncertain as to the costs and preferences of other voters.

The strategic model remains consistent with the view that, in large electorates, participation will result only if individuals have negative net costs of voting. We (Palfrey and Rosenthal, 1985) have shown that, in any symmetric equilibrium to the game of incomplete information, voters with significantly positive costs will abstain in very large electorates. In contrast, some voters with significantly positive costs will indeed vote in relatively small (e.g. 5,000 voters) electorates.

According to our theory, exactly how turnout varies with electorate size depends largely on the distribution of net voting costs across the electorate. Thus, in this paper, the key ingredient to our empirical study of the relationship between size and turnout is the estimation of this distribution across voters and across electorates. Specifically, we demonstrate that the equilibrium conditions from the voting game can be used to estimate this distribution, using turnout data from a cross-section of constituencies that vary in size. In addition to presenting the methodology for estimating the distribution of voting costs, we apply this technique to data on turnout in referenda for Oregon school districts.

Our empirical research adds to a body of striking empirical regularities regarding turnout. Perhaps foremost is, at the individual level, the strong relationship of turnout to sociodemographic variables. The well-to-do and, especially, the well-educated vote more heavily than those less endowed. (See, for example, Ashenfelter and Kelly, 1975; or Wolfinger and Rosenstone, 1980). As these variables may well be related to both the direct cost of voting and to the cost of processing information about alternatives (Frey, 1971), these empirical findings are hardly inconsistent with the Downsian framework. On the other hand, the findings provide little in the way of direct evidence that voter decisions reflect a Downsian calculus.

There is, however, more direct, institutional evidence that voting costs matter. The long-standing political debate over whether the poor, the working class, and the non-white have low participation because of poll taxes, 
literacy tests, limited hours for registration, and limited hours for voting is echoed in the empirical findings of Kousser (1974) and Wolfinger and Rosenstone (1980) that such variables do indeed affect turnout.

At a more maçroscopic level, recognition that costs matter is implicit in national practices of keeping the polls open for two consecutive days and paying roundtrip rail fare for citizens working in neighboring countries (Italy) and of making not-voting punishable (Australia and Belgium). In contrast, the United States is, in a set of 21 democracies, one of only 3 nations that both do not have compulsory voting and do not make registration automatic. Not surprisingly, the United States ranks 20th in turnout as a percentage of the voting age population (Glass, Squire, and Wolfinger, 1984). The reverse side of the coin is that reduced turnout can result when sanctions may be applied to those who turnout. For example, such a situation may have contributed to the exceptionally low level of turnout in the 1974 French presidential elections when the Communist party advocated abstention. A carrot-stick approach is represented by the practice of 'getting out the vote'. Costs are lowered and sanctions possibly avoided by accepting a ride to the polls. Finally, those who hope their chances are favored by high turnout express hopes for good weather.

These various indications that costs matter argue strongly that individuals do tradeoff costs and benefits, that there is far more rationality to turnout than that implied by the argument that turnout is largely explained by a sense of citizen duty implanted by family, school, or society.

In addition to identifying the empirical relationship between costs (and benefits) and turnout, it is important to establish whether the data supports the fundamental Downsian hypothesis of instrumental voting. That is, are voters' participation decisions responsive to the chance of being decisive?

Previous investigations of the role of instrumental voting have basically focused on the $p$ term. Does the probability of being decisive matter? Studies of Presidential elections, such as Ashenfelter and Kelly (1975), have generally concluded that the $\mathrm{p}$ term is irrelevant to turnout.

American presidential elections, unfortunately, are not a good choice of setting in which to examine the Downsian model, which has been developed only for two candidate plurality elections. Under the electoral college, the calculation of the probability that a given voter is decisive is far more complex than in direct two candidate elections. With the electoral college, the probability of being decisive is the joint probability that both a voter is decisive in the popular vote in the voter's state and that the state is pivotal in the electoral college. As a result, respondents' estimates as to whether the election is close may have little to do with their sense of being pivotal, since their estimates may reflect the respondents' views of the national outcome rather than the outcomes in the individuals' states.

In addition to problems generated by the electoral college, the analysis of 
turnout in presidential elections is often complicated by there being more than two candidates. Also, there are usually other races being voted on, the number and importance of these other races varying a great deal across precincts.

In contrast to the results for Presidential elections, studies for American Congressional elections (Silberman and Durden, 1975) and French parliamentary elections (Rosenthal and Sen, 1973) strongly indicate that closeness counts. Since the French data are not contaminated by multiple races and since these elections are generally two candidate plurality elections in jurisdictions of roughly equal size and for roughly similar stakes within each country, the results at first blush look like reasonable support for the Downsian model. 1

In fact, the observed regularity of the closeness factor in legislative elections is not necessarily easily reconciled with the Downsian model. The constituencies in legislative elections all involve large electorates. ${ }^{2}$ One can apply our earlier result (Palfrey and Rosenthal, 1985) that all voters with significant costs of voting will abstain and conclude that turnout should be unrelated to closeness in such samples of elections. Only if the distribution of voting costs is concentrated near zero, would the data be consistent with the Downsian model.

In this light, further studies of the instrumental voting hypothesis need to be informed by estimates of the distribution of the net cost of voting. If we are able to hold B roughly constant across electorates and elections, we can obtain estimates of this distribution using the equilibrium conditions to the voting game.

Empirical analysis based on the statistical model derived from these equilibrium conditions also permits us to address the 'puzzle' that turnout in local elections is unexpectedly high:

To simplify greatly, one should hardly be surprised that a presidential election in which two national political figures and two national parties engage in a three-month mass media campaign draws even three or four times the number of voters to the polls than does a non-partisan judicial campaign in which the candidates talk discreetly and a bit dully of the efficient administration of the courts. The wonder really is that it is not eight or ten times the number (Sorauf, 1968: 185).

The puzzle is resolved if the lower benefits in local elections are offset by the effects of group size on the probability of being decisive.

Group size (or constituency size in our case) may affect participation in many ways. One possibility, as noted in a more general context by Olson (1965), is that participation may be affected by a greater tendency to free ride in large groups. But other considerations, reflecting differences in sociological or psychological backgrounds or in social sanctions for not voting, may also explain any correlation between participation and consti- 
tuency size. That is, we may find systematic variation in the cost of voting when we compare small towns with large cities. Our approach is to assume invariance in these background factors and use the variation in turnout across constituencies to estimate the cost of voting. An important finding reported in this paper is that if one controls for the free rider effect on participation, as captured in our equilibrium conditions, then size as a separate independent variable has essentially no explanatory power. Our results do not appear to be affected by correlation of background factors with size. As a consequence, it appears that the instrumental theory of participation, in addition to providing some motivation for ad hoc regressions of turnout on closeness found in the literature, can be usefully applied to more rigorous studies of turnout.

In Section 2, we review those aspects of our theoretical papers that are used in our empirical work and develop our estimation strategy. The procedures we develop yield an estimate of the distribution of voter cost-benefit ratios. Our empirical work is based on the analysis of all school budget referenda in Oregon for the four years 1970-73. In Section 3, we discuss the data and linear turnout models of the type estimated by Romer and Rosenthal (1983). Romer and Rosenthal showed a strong dependence of turnout on size for this data. Our efforts here are directed to relating this observed relationship to a theoretical model. Empirical work based on the model of Section 2 is presented in the last three sections.

\section{Some basic theory of turnout}

In Palfrey and Rosenthal (1985), we developed a model in which voter utility was additive as in equation (1), the standard starting point of the literature. Without loss of generality, then, we can set $B=1$ and be concerned only with the distribution of the net cost benefit ratio $\mathrm{C}=(\mathrm{c}-\mathrm{d}) / \mathrm{B}$. We assume that $C$ varies across voters, voters know their own $C$ value, do not know each others' $C$ values, but do know the distribution of $C$.

Our model applies to the situation where the choice set for voters is limited to a pair of alternatives. ${ }^{3}$ These alternatives can be either two candidates in an election or the "yes" and "no" options in a referendum. In a more general version of our model, voters are not only uncertain about the distribution of costs but also uncertain as to how many other voters favor each alternative.

The equilibrium conditions for the general model do not lead to tractable mathematical forms that can be readily used in empirical work. Consider, however, the following special case. The voters know they are equally divided into two camps of size $\mathrm{M}$ each. Thus, the total electorate is of size $2 \mathrm{M}$. The same cost distribution applies to voters in both camps. A tied election is decided by the flip of a fair coin. 


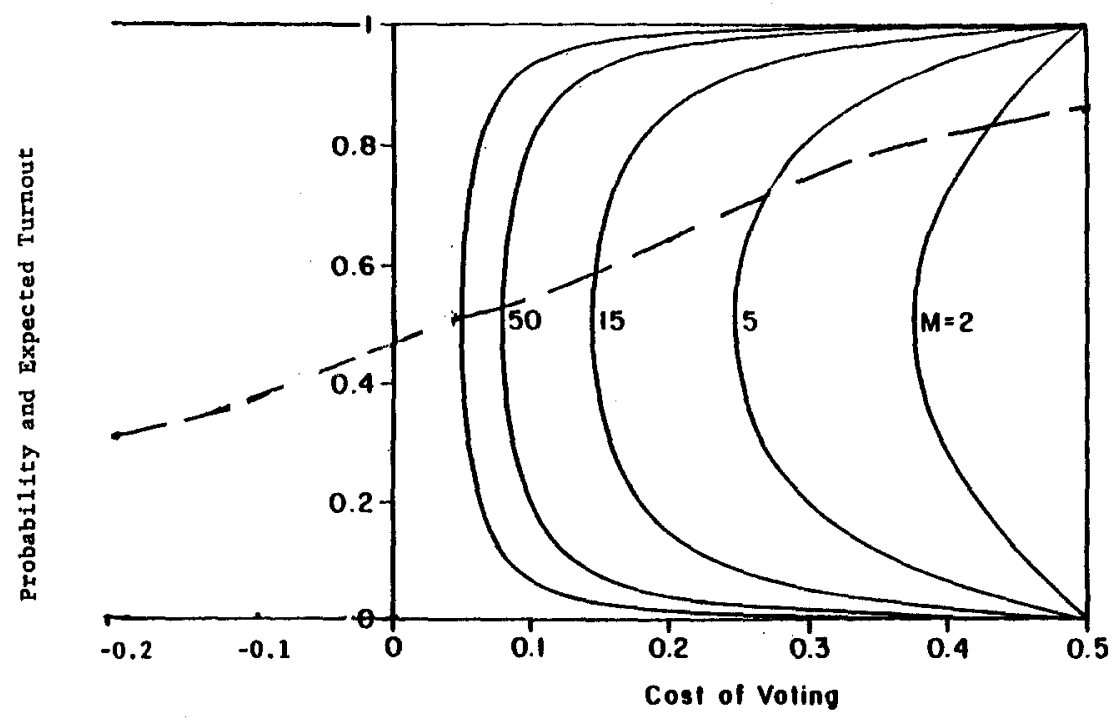

Figure 1. Equilibrium intersection: Unique equilibrium case

The equilibria to the participation game played by the voters can, in this special case and in general, be characterized by a critical cost $C^{*}$. If a voter's cost is below $\mathrm{C}^{*}$, the voter votes. If the cost is above $\mathrm{C}^{*}$, abstention results.

In our special case, a necessary condition for a symmetric equilibrium in which all voters use the same $C^{*}$ is given by:

$$
\begin{aligned}
2 C^{*}= & \sum_{k=0}^{M-1}\left(\begin{array}{c}
M-1 \\
k
\end{array}\right)\left(\begin{array}{l}
M \\
k
\end{array} q^{2 k}\right)(1-q)^{2 M-2 k-1}+\sum_{k=0}^{M-1}\left(\begin{array}{c}
M-1 \\
k
\end{array}\right)\left(\begin{array}{c}
M \\
k+1
\end{array}\right) \\
& q^{2 k+1}(1-q)^{2 M-2 k-2}
\end{aligned}
$$

where $\mathrm{q}$ is the probability that a randomly selected member of the electorate votes. (The first term on the right-hand side represents the probability that the voter's vote is decisive in breaking a tie; the second term, the probability of creating a tie. In either case, the voter gains half the benefit or $1 / 2$. Consequently, $2 C^{*}$ appears on the left-hand side.) Given that the decision rule is based on the critical value of $\mathrm{C}^{*}$, this probability can be obtained directly from the distribution of costs:

$$
\mathrm{q}=\mathrm{F}\left(\mathrm{C}^{*}\right)
$$

That is; equilibrium occurs at those points $\left(\mathrm{C}^{*}, \mathrm{q}\right)$ which simultaneously solve equations (2) and (3). ${ }^{4}$ Graphically, these are the points where the cumulative distribution function of cost-benefit ratios intersects the equilibrium condition (2). This is illustrated in Figure 1. The solid lines correspond to condition (2) for different electorate sizes, $M$. We have used a cumulative normal (dashed line) as an illustration of the cost distribution. 


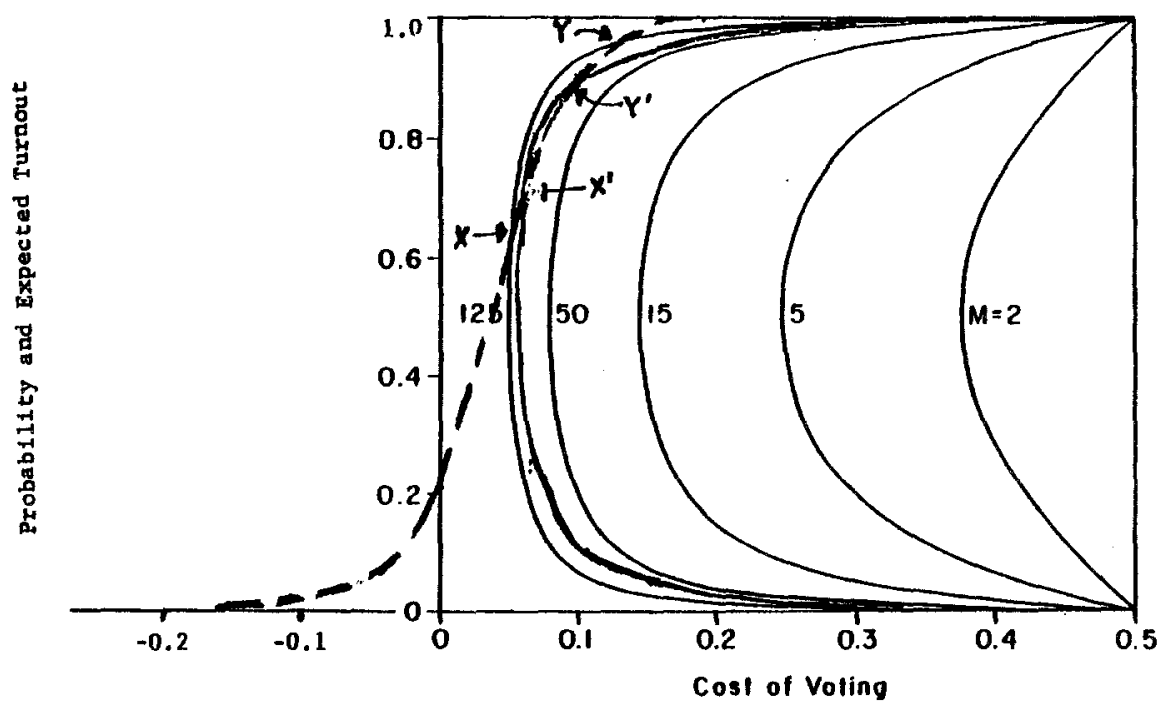

Figure 2. Equilibrium intersections: Multiple equilibria possible

The normal we have chosen has substantial variance. As a result, for each community size there is only one equilibrium. Moreover, as community size rises, expected turnout, q, falls, as intuition would have it. (Observe that the figure contains only a portion of the full Normal cumulative distribution function. Voters with costs above 0.5 have a dominant strategy of not voting. Those with costs below zero have a dominant strategy of voting.)

A contrasting distribution is shown in Figure 2. Compared to Figure 1, this distribution has the same mean but smaller variance. In this case, one can see that there are three equilibria for some values of $M$. For $M=125$ and $M=100$, two of the equilibria are labeled $X, Y$ and $X^{\prime}, Y^{\prime}$, respectively. The third equilibrium for each of these group sizes has $\mathrm{q}$ too close to 1.0 to show up on this scale graph. In the equilibrium with an intermediate turnout level, turnout is increasing in community size, contrary to intuition. (Compare $\mathrm{Y}^{\prime}$ to $\mathrm{Y}$.) Moreover, as some communities might be in high turnout equilibria and others in low turnout equilibria, the observed relationship of turnout to community size might become quite ambiguous. We discuss below how the possibility of multiple equilibria impinges on empirical estimation.

We turn now to indicating our methodology for using the equilibrium conditions in the estimation of voting costs. In our empirical work, we assume that observed turnout is equal to $\mathrm{q}$ - that is, we ignore intraobservation sampling fluctuations in the realization of an actual referendum. ${ }^{5}$ Consider then what one would be predicted to observe (according to the game-theoretic model) if all communities had the same cost distribution. Observed turnout and community size can be used to solve (2) 
for $C^{*}$. From this, one could plot $q$ versus $C^{*}$. This plot would be (in principle) a set of points perfectly fitting some cumulative distribution function. That is, the plot should show a monotonic progression like the dashed curve in Figure 1 or 2 . With a large number of observations from districts which have substantial variation in size (but which are otherwise relatively similar), the plot should accurately mirror the distribution of voting costs. Note that the plot of this cumulative distribution would be unaffected by the possibility of multiple equilibria.

Of course, we are not going to be so fortunate as to have points fitting nicely on the curve. Our first response to "error" was to find the best fitting curve assuming that the distribution of $\mathrm{C}^{*}$ was Normal. Since $\mathrm{N}^{-1}(\mathrm{q})$ will be linear in $\mathrm{C}^{*}$, one can simply regress the Normal inverse of the observed turnout proportion.

However, this simple "curve fitting" procedure is unsatisfactory because it does not explicitly model the source of the error. We model the error by assuming that the mean cost of voting varies across districts and that this mean is itself normally distributed with mean $\mathrm{h}$ and standard deviation $\sigma_{\mathrm{h}}$. Indexing elections by $t$, we have:

$$
\mathrm{h}_{\mathrm{t}} \sim \mathrm{N}\left(\mathrm{h}, \sigma_{\mathrm{h}}^{2}\right)
$$

The model assumes in addition that the intra-district distribution of costs is normal and has common standard deviation $\sigma$. Using standard notation, we denote by $\phi$ the unit Normal density and by $\Phi$ the unit Normal cumulative. Our model then is,

$$
\mathrm{q}_{\mathrm{t}}=\Phi \frac{\mathrm{c}_{\mathrm{t}}^{*}-\mathrm{h}_{\mathrm{t}}}{\sigma} \text { and } \mathrm{h}_{\mathrm{t}} \sim \mathrm{N}\left(\mathrm{h}, \sigma_{\mathrm{h}}^{2}\right)
$$

That is, given $q_{t}$ and $M_{t}$, (2) is used to solve for $C_{t}^{*}$. We then use (4) to estimate three parameters:

$\mathrm{h}=$ the interdistrict mean cost;

$\sigma_{\mathrm{h}}^{2}=$ the interdistrict variance of mean costs;

$\sigma^{2}=$ the intradistrict variance of individual costs.

This model can also be generalized to allow the mean cost $\mathbf{h}$ to be a linear function of exogenous variables. Such a function is used in later sections to incorporate variables that relate to cross-sectional variation in benefits.

The model is estimated by maximum likelihood. In this case, multiple equilibria do pose problems. Given $h_{t}$ (and the parameters $M_{t}, h, \sigma^{2}, \sigma_{h}^{2}$ ) we cannot solve uniquely for the observable variable $q_{t}$ (and for $C_{t}^{*}$, which is a function of $\mathrm{q}_{\mathrm{t}}$ and $\mathrm{M}_{\mathrm{t}}$ ). As a result, to apply standard methods for deriving 
the likelihood function, we must assume that for all communities with identical $M$ and $h_{t}$ values, the same equilibrium is always chosen. To support this assumption, we could argue that, in the case of multiple equilibria, the 'efficient' equilibrium with lowest $\mathrm{C}^{*}$ is always chosen as it is Schelling (1958) prominent. Our assumption does not require this argument, however. For example, all constituencies with 'high' $\mathrm{M}$ might choose a low cost equilibrium and all those with 'low' $M$ might choose a high cost equilibrium. In any event, for a fixed distribution of voting costs, multiple equilibria can arise only in very small jurisdictions. Consequently, this assumption should not be viewed as overly restrictive for our empirical work. A derivation of the likelihood function is available from the authors on request.

\section{Turnout in Oregon school districts: An initial view}

The empirical setting to which we apply our model is budget referenda in Oregon school districts from 1970-1973. There are two reasons why these budget referenda provide a particularly good environment for estimating our model. First, as shown by Romer and Rosenthal (1982), if the proposed expenditure is made by a budget-maximizing setter, the setter can be expected to make a proposal that splits the voters into two nearly equal camps. While the voters are not certain that each camp has exactly $\mathbf{M}$ potential voters, there is likely to be far less uncertainty about the division of opinion then there is as to what cost each individual voter has. Second, since all the referenda are about school budgets, the $B$ terms for individual voters will be roughly similar across observations. ${ }^{6}$ By having fairly similar B terms, we are avoiding the problems raised in Sorauf's comparison of the Presidency to a minor judicial post.

Several features of this referendum system are likely to have an effect on our estimation of the distribution of cost-benefit ratios, and we therefore control for them in our estimation procedure.

These factors are:

(1) In the case where a referendum fails, a limited number of retries can occur each year. It is reasonable to assume, if only because the possible loss of the school's custodial services becomes more salient as the start of the school year approaches (Romer and Rosenthal, 1983), that the cost-benefit ratio falls with each successive election. To capture this horizon effect, we use dummy variables to denote the first, second and third elections. The residual category is four or more elections.

Although both the setter and the agenda-setter acquire information from the realized yes-no division and turnout level in a failed referendum, we do not model potentially important feedback effects arising from this informa- 
tion. Such effects are only crudely proxied for by our dummy variables.

(2) There is more than one school district type. In addition to K-12 systems, there are districts that operate only elementary schools, and districts that operate only high schools.

The taxes required per household and the total benefits per household from school services will obviously be greater for the support of a K-12 school system with thirteen grade levels than for a high school system with only four grades. However, the cost of voting should be roughly the same in either case. As a result, the cost-benefit ratio should be lower in a K-12 system than in a four-grade high school only system. ${ }^{7}$ Consequently, we use dummies for school system types.

(3) Since school districts are not contiguous with political divisions (municipalities) there are no population data for school districts. ${ }^{8}$ For 1970-73 (but not later years), the state did publish data on voter registration by school district. This data is not exact; in at least some cases, it is obvious that approximations were made based on registrations in the municipalities and parts of municipalities that comprise a district. For this reason and because they studied turnout over a seven year period, Romer and Rosenthal (1983) used enrollment as their measure of size. Enrollment and registration are obviously highly correlated. In the type of linear regressions Romer and Rosenthal ran, results are robust to the measure of size used. In our work, the computation of $C^{*}$ is very sensitive to the value of $M$. We obtained far better results defining $M$ to be the number of registered voters. We use the registered voters definition of $M$ hereafter.

Having outlined the major features of the empirical setting, we can now turn to a discussion of the results of estimation. First, however, we give an overview of the data. We have a total of 1806 observations and a subset of 566 "close elections" observations where the "Yes" percentage in the referendum was between 45 and $55 \%$. It can be noted that, as is desirable from the viewpoint of experimental design, our data contains enormous variation. The registered voters vary from 17 in a small school district to 233,000 in Portland. Turnout varies from $4.5 \%$ to $96 \%$. The critical cost also has great variation. In the 566 close elections, the critical cost varied from 0.0027 to 0.136 .

The reason for constructing the close election sample was that equation (2) applies strictly only when the electorate is evenly split into M potential voters on each side. In fact, there are several reasons to expect some observations of referenda where the voters are not evenly divided between 'Yes' and 'No'. The two most apparent are that the Romer-Rosenthal model presumes the setter is (1) extremely well-informed and (2) has a single objective, to maximize the budget. If the setter is either not perfectly informed or has secondary objectives and constraints, one would not necessarily expect that the voters would be evenly split. If this occurs because of the 
second of these two reasons, the model implies that less than the maximum budget would be voted upon and significantly more than half the electorate would favor passage of the referendum. This might be the case, for example, in small school districts, where spendthrift budget setters are more easily monitored and, because of this relatively high visibility, bureaucratic objectives are less likely to be well-entrenched.

We chose to screen out observations that did not have a roughly even split of the vote. Preponderantly from small districts, these screened observations generally represented strong majorities favoring passage. Of the 1,240 observations that were not close elections, 1,003 had over 55\% 'Yes' while only 237 had under $45 \%$. In addition, the average number of registered voters increases from 3671 in the full sample to 4949 in the close election sample, despite the loss of three observations from Portland. Of the 430 observations with not more than 300 registered voters in the full sample, only 51 had close elections. Of the 47 observations with not more than 50 registered, only one had a close election.

Despite the differences in the size of districts, average turnout is about equal at $32 \%$ in both samples. This is an important observation. Theoretically, close elections ought to generate more turnout while increasing community size ought to lower turnout. Apparently, these two factors roughly offset each other as we move from the full sample to close elections.

\section{The size model vs. the cost model}

As we discussed in the introduction, regressions of measures of constituency size on measures of turnout may produce strong relationships, but they provide little guidance for the theoretical reasons that these relationships exist. According to the game theoretic model, this indirect relationship is due to a direct but non-linear effect of constituency size on 'critical cost levels', which in turn affect turnout. Thus, this 'cost model' differs from the standard 'size model' in that the latter is a reduced form model which conglomerates cost effects, sociological effects, and whatever else may enter into this relationship. In this section, we examine to what extent game theoretic considerations alone account for the total relationship between constituency size and turnout by substituting a variable of the estimated critical cost level for a variable measuring constituency size, while controlling for other factors such as district type.

Romer and Rosenthal (1983), in an initial attempt at describing the sizeturnout relationship, regressed the natural logarithm of turnout on the natural logarithm of size (also controlling for the same factors as we do). In Table 1 we present the estimation results of a comparable 'size model' which is similar to theirs, with the following exceptions: (1) Their sample 
Table 1. Comparison of cost model and size model ${ }^{\mathrm{a}}$ - Dependent variable: Ln(total voting/ registered)

\begin{tabular}{|c|c|c|c|c|}
\hline \multirow[t]{2}{*}{ Coefficient } & \multicolumn{2}{|l|}{ All elections } & \multicolumn{2}{|c|}{ Close elections } \\
\hline & Size model & Cost model & Size model & Cost model \\
\hline Constant & $\begin{array}{c}0.339 \\
(0.077)\end{array}$ & $\begin{array}{c}-0.875 \\
(0.067)\end{array}$ & $\begin{array}{c}0.569 \\
(0.125)\end{array}$ & $\begin{array}{c}-1.004 \\
(0.098)\end{array}$ \\
\hline Ln (registered) & $\begin{array}{c}-0.142 \\
(0.006)\end{array}$ & & $\begin{array}{c}-0.174 \\
(0.011)\end{array}$ & \\
\hline Critical cost & & $\begin{array}{c}7.311 \\
(0.430)\end{array}$ & & $\begin{array}{l}16.741 \\
(1.327)\end{array}$ \\
\hline Unified high ${ }^{b}$ & $\begin{array}{c}-0.027 \\
(0.034)\end{array}$ & $\begin{array}{c}-0.301 \\
(0.036)\end{array}$ & $\begin{array}{r}-0.126 \\
(0.055)\end{array}$ & $\begin{array}{c}-0.181 \\
(0.057)\end{array}$ \\
\hline Elementary ${ }^{b}$ & $\begin{array}{c}-0.124 \\
(0.021)\end{array}$ & $\begin{array}{c}-0.069 \\
(0.023)\end{array}$ & $\begin{array}{c}-0.043 \\
(0.039)\end{array}$ & $\begin{array}{c}-0.038 \\
(0.041)\end{array}$ \\
\hline Unified elem. ${ }^{b}$ & $\begin{array}{c}0.039 \\
(0.022)\end{array}$ & $\begin{array}{c}0.009 \\
(0.023)\end{array}$ & $\begin{array}{c}0.099 \\
(0.035)\end{array}$ & $\begin{array}{c}0.073 \\
(0.037)\end{array}$ \\
\hline 1st election ${ }^{b}$ & $\begin{array}{c}-0.559 \\
(0.062)\end{array}$ & $\begin{array}{c}-0.523 \\
(0.067)\end{array}$ & $\begin{array}{c}-0.531 \\
(0.091)\end{array}$ & $\begin{array}{c}-0.559 \\
(0.096)\end{array}$ \\
\hline 2nd election ${ }^{b}$ & $\begin{array}{c}-0.452 \\
(0.064)\end{array}$ & $\begin{array}{c}-0.450 \\
(0.069)\end{array}$ & $\begin{array}{c}-0.459 \\
(0.093)\end{array}$ & $\begin{array}{c}-0.493 \\
(0.099)\end{array}$ \\
\hline 3rd election ${ }^{b}$ & $\begin{array}{c}-0.368 \\
(0.068)\end{array}$ & $\begin{array}{c}-0.370 \\
(0.073)\end{array}$ & $\begin{array}{c}-0.302 \\
(0.100)\end{array}$ & $\begin{array}{c}-0.325 \\
(0.105)\end{array}$ \\
\hline $\mathbf{R}^{2}$ & .31 & .21 & .38 & .30 \\
\hline Number of observations & 1806 & 1806 & 566 & 566 \\
\hline
\end{tabular}

${ }^{a}$ Districts with no election or no registration data were deleted from the sample. Standard errors are in parentheses.

${ }^{b}$ These are $0-1$ dummy variables. $\mathrm{K}-12$ districts and proposals passing on fourth election or later are subsumed in the constant.

included winning elections only, while we report results based on both the full sample and our 'close elections' sample. (2) They present separate results for each year, while we pool all years. ${ }^{9}$ (3) They measure size indirectly by school district enrollment, while we measure size directly by voter registration. (4) They measure turnout by total voting divided by their size measure, while we do the same but use our measure of size.

The results obtained for our size model are reported in columns 1 and 3 of Table 1. Columns 2 and 4 of Table 1 report results of the same regressions except the size variable is replaced by our estimate of $\mathrm{C}^{*}$, the critical cost level. This is the 'cost model.' In comparing the results of the full election sample (columns 1 and 2) to the close election sample (columns 3 and 4), one can see that the coefficient on both size and cost is substantially greater in magnitude in the close election sample. In the full sample, the pure effect of size on cost is being confounded by the correlation between size and 
Table 2. Comparison of cost model and size model ${ }^{\mathrm{a}}$ - Dependent variable: $\mathrm{N}^{-1}$ (total voting/ registered)

\begin{tabular}{|c|c|c|c|c|}
\hline \multirow[t]{2}{*}{ Coefficient } & \multicolumn{2}{|l|}{ All elections } & \multicolumn{2}{|c|}{ Close elections } \\
\hline & Size model & Cost model & Size model & Cost model \\
\hline Constant & $\begin{array}{c}1.007 \\
(0.072)\end{array}$ & $\begin{array}{c}-0.170 \\
(0.061)\end{array}$ & $\begin{array}{c}1.211 \\
(0.114)\end{array}$ & $\begin{array}{c}-0.310 \\
(0.086)\end{array}$ \\
\hline Ln (registered) & $\begin{array}{r}-0.136 \\
(0.005)\end{array}$ & & $\begin{array}{c}-0.165 \\
(0.010)\end{array}$ & \\
\hline Critical cost & & $\begin{array}{c}8.183 \\
(0.390)\end{array}$ & & $\begin{array}{l}17.810 \\
(1.161)\end{array}$ \\
\hline Unified high ${ }^{\mathrm{b}}$ & $\begin{array}{c}-0.170 \\
(0.032)\end{array}$ & $\begin{array}{c}-0.223 \\
(0.033)\end{array}$ & $\begin{array}{c}-0.079 \\
(0.049)\end{array}$ & $\begin{array}{c}-0.121 \\
(0.050)\end{array}$ \\
\hline Elementary ${ }^{b}$ & $\begin{array}{c}-0.121 \\
(0.020)\end{array}$ & $\begin{array}{c}-0.076 \\
(0.021)\end{array}$ & $\begin{array}{c}-0.024 \\
(0.035)\end{array}$ & $\begin{array}{c}-0.035 \\
(0.036)\end{array}$ \\
\hline Unified Elem. ${ }^{b}$ & $\begin{array}{c}0.025 \\
(0.020)\end{array}$ & $\begin{array}{c}0.010 \\
(0.021)\end{array}$ & $\begin{array}{c}0.089 \\
(0.050)\end{array}$ & $\begin{array}{c}0.069 \\
(0.033)\end{array}$ \\
\hline 1st election ${ }^{b}$ & $\begin{array}{c}-0.545 \\
(0.058)\end{array}$ & $\begin{array}{c}-0.527 \\
(0.061)\end{array}$ & $\begin{array}{c}-0.513 \\
(0.082)\end{array}$ & $\begin{array}{c}-0.546 \\
(0.085)\end{array}$ \\
\hline 2nd election ${ }^{\mathrm{b}}$ & $\begin{array}{c}-0.448 \\
(0.069)\end{array}$ & $\begin{array}{c}-0.451 \\
(0.062)\end{array}$ & $\begin{array}{c}-0.448 \\
(0.084)\end{array}$ & $\begin{array}{c}-0.483 \\
(0.086)\end{array}$ \\
\hline 3 rd election ${ }^{b}$ & $\begin{array}{r}-0.380 \\
(0.064)\end{array}$ & $\begin{array}{c}-0.384 \\
(0.066)\end{array}$ & $\begin{array}{c}-0.324 \\
(0.090)\end{array}$ & $\begin{array}{c}-0.345 \\
(0.092)\end{array}$ \\
\hline $\mathbf{R}^{2}$ & .31 & .26 & .39 & .37 \\
\hline Number of observations & 1806 & 1806 & 566 & 566 \\
\hline
\end{tabular}

${ }^{a, b}$ See notes to Table 1 .

closeness. Consequently, the effect of size is underestimated when there is no control for the winning margin. ${ }^{10}$

According to the game theoretic cost model, if voting costs are approximately normally distributed, a more appropriate dependent variable is the normal inverse of turnout, rather than the ad hoc log specification. Thus, according to our theory, this better specification should substantially improve the explanatory power of the cost model relative to that of the size model. The results of the normal inverse model are given in Table 2 . As expected, the $\mathrm{R}^{2}$ for the cost models increases substantially, while the size model is unaffected. When we look at the close election sample, which partially controls for winning margin, the cost model is found to explain practically all of the variance accounted for by the electorate size.

The variation in turnout also reflects how near one is to having the 'clock run out'. Turnout is least in initial elections and rises on each subsequent try. Also as expected, turnout is lower in those school districts that do not operate K-12 systems, and is least of all in those districts that operate only high schools. However, there is an anomaly in the estimates for districts that 
operate K-12 systems by paying high school tuition to other systems. In the full sample, as expected, they had roughly the same turnout as pure K-12 systems. But, in the close elections sample, they had significantly higher turnout. Not too much, however, should be made of these school type estimates. The effects are all weak compared to those related either to cost or the 'clock running out', and significant coefficients are a consequence of large sample size.

Despite this clear evidence that turnout and cost are closely related, these regressions suffer from an implausible error structure. While it is true that equations (2) and (3) refer only to expected turnout, not its actual realization, and, in small districts, there might be some random variation about expected turnout, it is more plausible that the source of 'noise' is in differences in the cost structure across school districts. Consequently, we turn to the random means model, in which interdistrict variations in cost structure are explicitly modelled.

\section{The random means model}

Results for the random means model are shown for the full sample in Table 3 and for close elections in Table 4. Results for the dummy variables parallel those found with the OLS regressions. The key points concern the comparison between the close elections and the full sample. First, the loglikelihood per case is considerably higher in the close elections sample than in the full sample. This parallels the results of Tables 1 and 2. Second, when we enter the logarithm of the number of registered voters as part of the mean cost vector (column 4), the estimated coefficient is highly significant in the full sample. But, importantly, in close elections the coefficient is not significant, even at the .10 level, and its estimate is only one-fifth the value of the estimate in the full sample.

This result can be interpreted by noting that, in the full sample, the coefficient will proxy for the relationship between closeness and size. Introducing the lower turnouts in non-close small districts in (2) generates a cost that is too high. This is 'corrected' for by the size variable. In contrast, for close elections, there is no independent effect for the size variable (at least in this functional specification) that is not captured by the cost model.

Because size appears to have no independent effect and because introducing it raises the standard errors of the other coefficients, we rely on column (3) for further discussion of the close election results. First, our estimates can be used to derive estimates of the proportion of the population who have negative costs. In school districts that operate K-12 systems, we estimate that costs are negative for $18 \%$ of the population in first elections, $20 \%$ in second elections, $25 \%$ in third elections, and $37 \%$ in the case of 
Table 3. The random means model, $1970-73$, all observations

\begin{tabular}{|c|c|c|c|c|}
\hline & \multicolumn{4}{|l|}{ Model } \\
\hline & (1) & (2) & (3) & (4) \\
\hline \multicolumn{5}{|l|}{$\begin{array}{l}\text { Coefficients of } \\
\text { variables in interdistrict } \\
\text { mean cost, } h\end{array}$} \\
\hline - Constant & $\begin{array}{c}0.0818 \\
(0.0019)\end{array}$ & $\begin{array}{c}0.0215 \\
(0.0067)\end{array}$ & $\begin{array}{c}0.0203 \\
(0.0063)\end{array}$ & $\begin{array}{r}-0.0537 \\
(0.0166)\end{array}$ \\
\hline - Unified high & & & $\begin{array}{c}0.0209 \\
(0.0035)\end{array}$ & $\begin{array}{c}0.0281 \\
(0.0053)\end{array}$ \\
\hline - Elementary & & & $\begin{array}{c}0.0089 \\
(0.0020)\end{array}$ & $\begin{array}{c}0.0173 \\
(0.0033)\end{array}$ \\
\hline - Unified & & & $\begin{array}{c}-0.0028 \\
(0.0023)\end{array}$ & $\begin{array}{r}-0.0059 \\
(0.0035)\end{array}$ \\
\hline - 1st election & & $\begin{array}{c}0.0610 \\
(0.0069)\end{array}$ & $\begin{array}{c}0.0566 \\
(0.0065)\end{array}$ & $\begin{array}{c}0.0900 \\
(0.0111)\end{array}$ \\
\hline-2 nd election & & $\begin{array}{c}0.0505 \\
(0.0072)\end{array}$ & $\begin{array}{c}0.0470 \\
(0.0067)\end{array}$ & $\begin{array}{c}0.0732 \\
(0.0108)\end{array}$ \\
\hline - 3rd election & & $\begin{array}{c}0.0431 \\
(0.0076)\end{array}$ & $\begin{array}{c}0.0400 \\
(0.0073)\end{array}$ & $\begin{array}{c}0.0620 \\
(0.0114)\end{array}$ \\
\hline$-\ln$ (reg. voters) & & & & $\begin{array}{c}0.0099 \\
(0.0018)\end{array}$ \\
\hline $\begin{array}{l}\text { Interdistrict mean } \\
\text { cost std. dev., } \sigma_{\mathrm{h}}\end{array}$ & $\begin{array}{c}0.0395 \\
(0.0013)\end{array}$ & $\begin{array}{c}0.0359 \\
(0.0013)\end{array}$ & $\begin{array}{c}0.0343 \\
(0.0012)\end{array}$ & $\begin{array}{c}0.0518 \\
(0.0032)\end{array}$ \\
\hline $\begin{array}{l}\text { Intradistrict cost std. } \\
\operatorname{dev}_{.}, \sigma\end{array}$ & $\begin{array}{l}0.1134 \\
(0.0038)\end{array}$ & $\begin{array}{c}0.1062 \\
(0.0038)\end{array}$ & $\begin{array}{c}0.1032 \\
(0.0038)\end{array}$ & $\begin{array}{c}0.0160 \\
(0.0102)\end{array}$ \\
\hline Log-likelihood & 1438.66 & 1497.45 & 1532.95 & 1553.81 \\
\hline $\mathrm{N}=\begin{array}{l}\text { number of } \\
\text { observations }\end{array}$ & 1806 & 1806 & 1806 & 1806 \\
\hline Log-likelihood/N & .797 & .829 & .849 & .860 \\
\hline
\end{tabular}

fourth or higher elections. These estimates should be taken with some caution, since our estimated cost distribution has low variance and increases sharply near the mean. Nonetheless, since average turnout, over all elections is $32 \%$, many voters appear to vote for instrumental reasons and not for either a sense of 'citizen duty' or for avoidance of regret (Ferejohn and Fiorina, 1974). Many of the registered voters who vote appear to regard voting as costly but instrumentally effective.

Second, related to our result that there appears to be many instrumental voters, turnout shifts rapidly with variations in community size. For example, the distribution drawn in Figure 2 is in fact the distribution which corresponds to our estimate of the intra-district standard error of 0.049 and to a representative mean cost of 0.04 . It can be seen that turnout is about $20 \%$ 
Table 4. The random means model, 1970-73, close elections ${ }^{\mathrm{a}}$

\begin{tabular}{|c|c|c|c|c|}
\hline & \multicolumn{4}{|l|}{ Model } \\
\hline & (1) & (2) & (3) & (4) \\
\hline \multicolumn{5}{|c|}{$\begin{array}{l}\text { Coefficients of } \\
\text { variables in interdistrict } \\
\text { mean cost, } h\end{array}$} \\
\hline - Constant & $\begin{array}{c}0.0435 \\
(0.0014)\end{array}$ & $\begin{array}{c}0.0170 \\
(0.0024)\end{array}$ & $\begin{array}{c}0.0170 \\
(0.0054)\end{array}$ & $\begin{array}{c}0,0038 \\
(0.0119)\end{array}$ \\
\hline - Unified high & & & $\begin{array}{c}0.0053 \\
(0.0023)\end{array}$ & $\begin{array}{r}0.0056 \\
(0.0027)\end{array}$ \\
\hline - Elementary & & & $\begin{array}{c}0.0027 \\
(0.0018)\end{array}$ & $\begin{array}{c}0.0032 \\
(0.0021)\end{array}$ \\
\hline - Unified & & & $\begin{array}{r}-0.0037 \\
(0.0017)\end{array}$ & $\begin{array}{r}-0.0046 \\
(0.0020)\end{array}$ \\
\hline - 1st election & & $\begin{array}{c}0.0285 \\
(0.0063)\end{array}$ & $\begin{array}{c}0.0273 \\
(0.0055)\end{array}$ & $\begin{array}{c}0.0316 \\
(0.0061)\end{array}$ \\
\hline - 2nd election & & $\begin{array}{c}0.0248 \\
(0.0064)\end{array}$ & $\begin{array}{c}0.0240 \\
(0.0056)\end{array}$ & $\begin{array}{r}0.0276 \\
(0.0068)\end{array}$ \\
\hline - 3rd election & & $\begin{array}{c}0.0173 \\
(0.0068)\end{array}$ & $\begin{array}{c}0.0169 \\
(0.0061)\end{array}$ & $\begin{array}{r}0.0195 \\
(0.0071)\end{array}$ \\
\hline - In (reg. voters) & & & & $\begin{array}{r}0.0018 \\
(0.0013)\end{array}$ \\
\hline $\begin{array}{l}\text { Interdistrict mean } \\
\text { cost std. dev, } \sigma_{\mathrm{h}}\end{array}$ & $\begin{array}{c}0.0169 \\
(0.0009)\end{array}$ & $\begin{array}{c}0.0157 \\
(0.0008)\end{array}$ & $\begin{array}{c}0.0146 \\
(0.0007)\end{array}$ & $\begin{array}{c}0.0168 \\
(0.0019)\end{array}$ \\
\hline $\begin{array}{l}\text { Intradistrict cost std. } \\
\text { dev., } \sigma\end{array}$ & $\begin{array}{c}0.0532 \\
(0.0027)\end{array}$ & $\begin{array}{c}0.0518 \\
(0.0024)\end{array}$ & $\begin{array}{c}0.0492 \\
(0.0022)\end{array}$ & $\begin{array}{r}0.0573 \\
(0.0067)\end{array}$ \\
\hline Log-likelihood & 514.08 & 543.27 & 555.67 & 556.96 \\
\hline $\mathrm{N}=\begin{array}{l}\text { number of } \\
\text { observations }\end{array}$ & 566 & 566 & 566 & 566 \\
\hline Log-likelihood/N & .908 & .960 & .982 & .984 \\
\hline
\end{tabular}

${ }^{a}$ Elections where $1 \%$ Yes $-\%$ Nol $\leq 10.0$.

in very large communities, about $60 \%$ when $M=125$, and nearly $100 \%$ when $\mathrm{M}=50$.

Third, we obtain an estimate of the average cost-benefit ratio of voting, which we find to be in the range of .02 to .04 . Romer and Rosenthal (1982) indicate that, when voters are threatened with the shutdown of the schools, spending is about $\$ 150$ per household (in K-12 districts) higher than it would be were no such threat possible. And, of course, the 'dollar equivalent' of actually closing the schools against operating them must be higher than $\$ 150$. If voting takes one half-hour, our estimate of the average cost of voting corresponds to an after-tax wage of about $\$ 5.00$ per hour, using a cost-benefit ratio $\left(\mathrm{C}^{*}\right)$ of 0.63 and the $\$ 150$ figure for $\mathrm{B}$. While the above calculations are obviously 'back of the envelope', they do seem to be in the right ballpark. 
Fourth, it should be noted that the intradistrict standard deviation is large relative to the mean cost standard deviation. Most of the variation in costs is not between communities but between individuals. For $M>50,000$, turnout is not estimated to be substantially different from the proportion of voters with zero or negative costs. This is true for our estimated standard error even were the mean cost zero, the point where the Normal curve rises most sharply. So, for the variation in cost-benefit ratios we find, one would not expect to find a strong relationship between closeness and turnout in very large jurisdictions.

\section{Conclusion}

We believe we have established, both theoretically and empirically, how turnout is related to the size of jurisdiction. This relationship results primarily from the free rider aspects of voting. Because we have a wellspecified theory and not just a descriptive hypothesis, we have been also able to estimate the distribution of voting costs.

The fact that the effects of size appear to be introduced mainly through our equilibrium model is our most important finding. Not only does it support the model, but it also leads to the substantive conclusion that the fundamental calculus of voting in very small electorates is not dramatically different from large electorates. The net costs of voting in small electorates do not appear to be significantly lowered by lower anomie, greater 'citizen duty,' or higher sanctions from not being noticed by their fellow citizens. Rather, higher turnout occurs because the free rider problem is less severe in smaller groups. While sociological factors may well impact upon the general distribution of voting costs, any sociological distinctions between large groups and small groups appear to be largely captured by our model of the free rider problem.

Our results also have some normative implications. If one values turnout per se, small jurisdictions make sense. However, turnout will also be driven up by any mechanism that closely divides the electorate between distinct alternatives. A referendum system in which a budget-maximizing agent can make a proposal against a generally low budget status quo works exactly this way. As these budget-maximizing agents are more likely to arise in large communities (another consequence of free-riding), the direct effect of size on turnout is partially masked by the increase in turnout brought about by manipulative agenda-setting in larger jurisdictions. So small districts have two virtues. They elicit participation and they tend to generate median proposals that avoid divisive contests.

With specific reference to schools, these benefits of smallness must be traded off against other considerations, such as the social and racial integra- 
tion effects of larger districts and the ability of larger districts to deliver a larger menu of services. It is not surprising, however, that large district proponents are legion among the suppliers of educational services. They are potential beneficiaries of the free rider problem in participation.

\section{NOTES}

1. Barzel and Silberberg (1973), in a linear regression that includes size, find that closeness counts in gubernatorial contests.

2. If voters looked beyond their constituencies to control of the national parliament in making a decision, the relevant electorate size would be even larger.

3. In the Oregon referenda, the choice is between the school board's proposed budget and a reversion level (Romer and Rosenthal, 1982).

4. See Palfrey and Rosenthal (1985) for detailed exposition of these equilibrium conditions.

5. Regressing the squared residuals from the 'Close Elections' regressions of Tables 1 and 2 on the logarithm of the number of registered voters produced $\mathrm{R}^{2}$ values less than .015 . Consequently, there does not appear to be substantial heteroskedasticity. The absence of heteroskedasticity implies little is to be gained from modeling sampling fluctuations.

6. The agenda control model of Romer and Rosenthal (1982) indicates that the B terms will depend heavily on the reversion level. We simply embedded these reversion effects in the random distribution of $h_{t}$. Presumably, school districts with low reversions and, hence, high proposals will have relatively large $B$ terms. Hence, the cost-benefit ratio will be smaller in those districts. This can be partially captured in our model by a smaller $h_{1}$ term, assuming that these reversion effects are independent of $\mathrm{M}$. However, due to the low estimate of across-district variance, we suspect that there is insufficient variation in reversion levels to account for much of the turnout differences.

7. In some localities, elementary and high school district elections may be held on the same day. Because linking elementary and high school districts is a major data processing task, we have not taken this complication into account in our work. The elections typically are held on days other than the election days for Federal and state offices.

8. For the 1970 census, the Office of Education produced a school district census tape, but this tape excludes about half the school districts in Oregon since it was restricted to districts with more than 250 students.

9. Our pooled results are basically similar across years. The $R^{2}$ values for the pooled regressions are slightly less than the average of those for yearly elections. Results for winning elections only are similar to those reported here.

10. Note that size and cost are both 'significant' in the full sample. They remain significant in regressions run for the 'not close' subsample. This empirical result merits closer study since one might hypothesize that size and cost should have no relationship to turnout in referenda that were not closely contested. To address this question from the perspective of our model, one would need to begin with a pair of equations similar to (2) when the camps are of unequal sizes $M_{1}$ and $M_{2}$. (See Palfrey and Rosenthal, 1985.)

Unfortunately, only $\mathbf{M}_{1}+\mathbf{M}_{2}$, the total number of registered voters, is observable. To avoid estimating one parameter per observation $\left(\mathrm{M}_{1}\right)$ from the data, one could constitute a panel by assuming that the ratio of $\mathrm{M}_{1}$ to $\mathrm{M}_{2}$ was constant, say, in the first election in each year. But even under such an assumption, the number of waves in the panel would be small, and one would be likely to have strongly biased estimates of all parameters given the well-known incidental parameters problem with non-linear models (Chamberlain, 1980). These econometric problems forced us to eschew estimation of the more general model and to make the restrictive assumption that $\mathrm{M}_{1}=\mathbf{M}_{2}$. 


\section{REFERENCES}

Ashenfelter, O., and S. Kelley, Jr. (1975). Determinants of participation in presidential elections. Journal of Law and Economics 18: 695-733.

Barzel, Y., and Silberberg, E. (1973). Is the act of voting rational? Public Choice 16: 51-59.

Chamberlain, G. (1980). Analysis of covariance with qualitative data. Journal of Economic Studies 47: 225-238.

Downs, A. (1957). An economic theory of democracy. New York: Harper and Row.

Ferejohn, J., and Fiorina, M. (1974). The paradox of not voting: A decision theoretic analysis. American Political Science Review 68: 525-536.

Frey, B.S. (1971). Why do high income people participate more in politics? Public Choice 11: 101-106.

Glass, D., Squire, P., and Wolfinger, R. (1984). Voter turnout: An international comparison. Public Opinion: 49-55.

Kousser, J.M. (1974). The shaping of Southern politics: Suffrage restriction and the establishment of the one party South 1880-1910. New Haven: Yale University Press.

Ledyard, J. (1984). The pure theory of large two-candidate elections. Public Choice 44: 7-43.

Olson, M. (1965). The logic of collective action. New York: Schocken.

Palfrey, T.R., and Rosenthal, H. (1983). A strategic calculus of voting. Public Choice 41: $7-53$.

Palfrey, T.R., and Rosenthal, H. (1985). Voter participation and strategic uncertainty. American Political Science Review 79: 62-78.

Patterson, S.C., and Caldeira, G.A. (1983). Getting out the vote: participation in gubernatorial elections. American Political Science Review 77: 675-689.

Riker, W., and Ordeshook, P.C. (1968). A theory of the calculus of voting. American Political Science Review 62: 25-42.

Romer, T., and Rosenthal, H. (1982). Median voters or budget maximizers: Evidence from school expenditure referenda. Economic Inquiry 20: 556-578.

Romer, T., and Rosenthal, H. (1983). Voting and spending: Some empirical relationships in the political economy of local public finance. In G. Zodrow, (Ed.), Local provision of public services: The Tiebout model after twenty-five years, New York: Academic Press.

Rosenthal, H., and Sen, S. (1973). Electoral participation in the French Fifth Republic. American Political Science Review 67: 29-54.

Schelling, T. (1958). The strategy of conflict. Cambridge: Harvard University Press.

Silberman, J., and Durden, G. (1975). The rational behavior theory of voter participation: The evidence from congressional elections. Public Choice 23: 101-108.

Sorauf, F.J. (1968). Party politics in America. Boston: Little Brown.

Wolfinger, R., and Rosenstone, S. (1980). Who votes? New Haven: Yale University Press. 